\title{
pOpLA - AN INTEGRATED SOFTWARE SYSTEM FOR TEXTURE ANALYSIS
}

JOHN S. KALLEND ${ }^{1}$, U.F. KOCKS ${ }^{2}$, A.D. ROLLETT ${ }^{2}$ and H.-R. WENK ${ }^{3}$

${ }^{1}$ Illinois Institute of Technology, Chicago, IL 60616, USA

${ }^{2}$ Los Alamos National Laboratory, Los Alamos, NM 87545, USA

${ }^{3}$ University of California, Berkeley, CA 94720 , USA

The quantitative analysis of texture data is a computationally intensive task requiring mathematically sophisticated techniques. The small market has made commercial distribution of texture analysis software expensive and, on the whole, unsatisfactory. Additionally, most of the software that has been made available has been specific to one or another brand of $x$-ray hardware and associated computer. In some cases, proprietary data structures have made information interchange almost impossible.

The intent of this paper is to make available, at nominal cost, popLA (preferred orientation package - Los Alamos), a texture analysis software system that has been assembled by the authors for their own use. The system is designed to be implemented on the most widely available computer hardware, the IBM ${ }^{\mathrm{tm}} \mathrm{PC}$ and compatibles operating under MS-DOS. It provides graphical output on a PC monitor, hardcopy on a laser printer or plotter, and data files in ASCII format to provide for easy information interchange and to be used in properties prediction. It requires a PC compatible personal computer running under DOS version 3.1 or later, and equipped with a hard disk, mathematics coprocessor, $480 \mathrm{kB}$ of available RAM and, for screen graphics, an EGA or VGA monitor. Hardcopy can be to a laser printer compatible with either the HP Laserjet series II graphics commands or the Adobe Postscript language, or to any plotter or plotter emulator compatible with the HPGL plotter graphics language. Some of the features of the package are described below. For a more detailed description, see ref. ${ }^{6}$

\section{DATA REQUIREMENTS AND DATA STRUCTURE}

The software requires input in the form of experimental pole figure files containing data that have been corrected for background, defocussing etc. The pole figures may be complete, or partial (reflection) pole figures to a tilt of at least $70^{\circ}$. The following operations are available for the pole figure data: symmetry analysis and rotation or tilting to compensate for sample misalignment, smoothing, symmetrization, and (in the case of incomplete pole figures) completion in a crystallographically consistent way by harmonic analysis.

The data file structure is consistent between pole figures and ODF files, containing a header which identifies the sample, pole figure or section, and the 
domain over which the data are available, scaling factor etc. This file structure allows one display program to handle both pole figures and ODFs, and also facilitates easy data transfers between different laboratories. The data themselves are four-digit integers scaled (as far as their values allow) so that random $=100$. Table 1 shows the header and first few lines of a (111) pole figure measured to $80^{\circ}$ tilt angle.

TABLE 1. Beginning of typical $\{111\}$ pole figure file. The second line contains parameters describing the data domain, "random" level etc.

\begin{tabular}{|c|c|c|c|c|c|c|c|c|c|c|c|c|c|c|c|c|c|}
\hline $\begin{array}{l}\text { CU ROI } \\
(111)\end{array}$ & $\begin{array}{l}5.0 \\
5.0 D\end{array}$ & $\begin{array}{r}80 \% \\
80\end{array}$ & & 5.03 & 50.0 & 11 & $2-1$ & 3 & 00 & 13 & & & & & & & \\
\hline 3 & 3 & 3 & 3 & 3 & 3 & 3 & 3 & 3 & 3 & 3 & 3 & 3 & 3 & 3 & 3 & 3 & 3 \\
\hline 3 & 3 & 3 & 3 & 3 & 3 & 3 & 3 & 3 & 3 & 3 & 3 & 3 & 3 & 3 & 3 & 3 & 3 \\
\hline 3 & 3 & 3 & 3 & 3 & 3 & 3 & 3 & 3 & 3 & 3 & 3 & 3 & 3 & 3 & 3 & 3 & 3 \\
\hline 3 & 3 & 3 & 3 & 3 & 3 & 3 & 3 & 3 & 3 & 3 & 3 & 3 & 3 & 3 & 3 & 3 & 3 \\
\hline 2 & 3 & 2 & 3 & 2 & 2 & 3 & 2 & 2 & 2 & 3 & 2 & 2 & 2 & 2 & 3 & 2 & 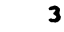 \\
\hline 3 & 4 & 4 & 4 & 3 & 3 & 4 & 3 & 2 & 2 & 3 & 3 & 3 & 2 & 3 & 3 & 3 & 2 \\
\hline 3 & 4 & 3 & 3 & 3 & 3 & 2 & 2 & 3 & 3 & 2 & 3 & 3 & 3 & 5 & 4 & 5 & 4 \\
\hline 4 & 3 & 3 & 4 & 3 & 5 & 3 & 3 & 3 & 3 & 3 & 2 & 4 & 3 & 4 & 2 & 2 & 4 \\
\hline 3 & 4 & 3 & 2 & 3 & 4 & 3 & 1 & 4 & 4 & 3 & 3 & 4 & 5 & 5 & 6 & 6 & 6 \\
\hline 7 & 6 & 5 & 6 & 6 & 5 & 5 & 4 & 4 & 4 & 4 & 3 & 3 & 3 & 4 & 3 & 3 & 3 \\
\hline 2 & 3 & 3 & 3 & 3 & 2 & 3 & 4 & 4 & 4 & 4 & 5 & 6 & 6 & 5 & 7 & 8 & 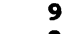 \\
\hline 8 & 8 & 7 & 8 & 8 & 7 & 8 & 7 & 7 & 5 & 5 & 4 & 5 & 4 & 4 & 4 & 2 & 3 \\
\hline 5 & 4 & 5 & 4 & 4 & 5 & 4 & 5 & 5 & 6 & 8 & 9 & 10 & 13 & 16 & 20 & 24 & 28 \\
\hline 33 & 35 & 33 & 28 & 21 & 18 & 13 & 11 & 9 & 8 & 6 & 5 & 5 & 4 & 4 & 4 & 3 & 2 \\
\hline 3 & 3 & 3 & 4 & 4 & 4 & 4 & 5 & 6 & 8 & 9 & 11 & 13 & 18 & 22 & 29 & 33 & 38 \\
\hline 40 & 38 & 35 & 33 & 27 & 21 & 19 & 17 & 13 & 10 & 9 & 8 & 8 & 6 & 4 & 5 & 4 & \\
\hline 5 & 6 & 6 & 6 & 6 & 6 & 7 & 9 & 11 & 14 & 19 & 28 & 37 & 53 & 75 & 103 & 138 & 175 \\
\hline 204 & 220 & 212 & 185 & 142 & 102 & 68 & 43 & 29 & 19 & 15 & 9 & 8 & 7 & 7 & & & \\
\hline $\begin{array}{r}4 \\
262\end{array}$ & $\begin{array}{r}5 \\
254\end{array}$ & $\begin{array}{r}5 \\
223\end{array}$ & $\begin{array}{r}5 \\
179\end{array}$ & $\begin{array}{r}6 \\
134\end{array}$ & $\begin{array}{r}6 \\
96\end{array}$ & $\begin{array}{r}7 \\
70\end{array}$ & $\begin{array}{r}8 \\
46\end{array}$ & $\begin{array}{l}12 \\
38\end{array}$ & $\begin{array}{l}15 \\
27\end{array}$ & $\begin{array}{l}24 \\
21\end{array}$ & $\begin{array}{l}33 \\
15\end{array}$ & $\begin{array}{l}51 \\
12\end{array}$ & $\begin{array}{l}78 \\
10\end{array}$ & $\begin{array}{r}116 \\
8\end{array}$ & $\begin{array}{r}160 \\
7\end{array}$ & $\begin{array}{r}205 \\
6\end{array}$ & $\begin{array}{r}249 \\
6\end{array}$ \\
\hline
\end{tabular}

\section{ODF ANALYSIS}

ODF analysis is available using both the spherical harmonic method ${ }^{1,2}$ (even terms only) for cubic, tetragonal, hexagonal and orthorhombic crystals, and by a WIMV based method ${ }^{3}$ for cubic, tetragonal, trigonal, hexagonal, and orthorhombic crystals. ODF output is as an ASCII file containing ODF sections in the conventions of Bunge ${ }^{1}$, Roe $^{2}$ or Kocks ${ }^{4}$ according to the user's choice. The ODF files may be used to produce graphical output (see below) or "weighted grains" files that may be used for subsequent use in modelling texture evolution and anisotropy of properties 5 .

\section{GRAPHICAL OUTPUT}

Graphical output of pole figure and ODF data is available in a variety of formats. Polar plots of pole figures and ODF sections (both normal and oblique ${ }^{4}$ ) may be made in stereographic or equal-area projection'. Both grey-shades and color graphics are available with an appropriate computer monitor, and grey shades are available in hardcopy on a laser printer (Figures 1-3). Plotter output is available as contour plots in equal area or stereographic projection for both pole figures and 
ODF sections, or in the more conventional form of Cartesian plots for ODF sections.

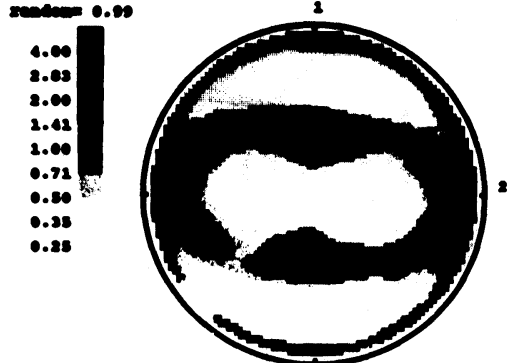

122

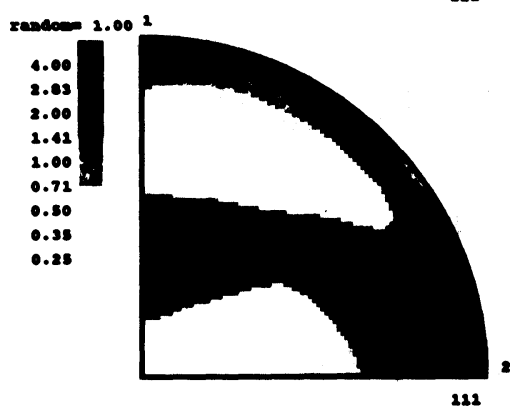

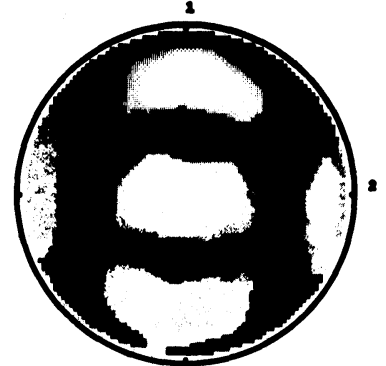

200

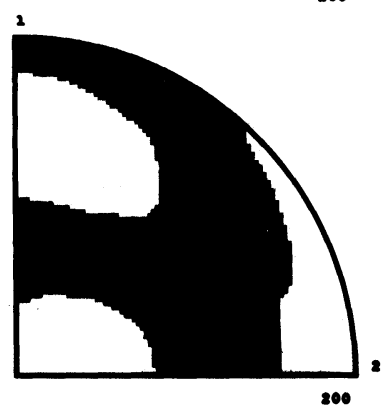

Figure 1. Measured equal-area incomplete pole figures (above) from a misaligned sample, and the same data (below) after rotation, symmetrization and completion.

\section{PROPERTIES PREDICTIONS}

Anisotropy of properties is of recurring interest in texture research, and some capability for properties prediction is included in popLA. The "weighted grains" files provide an economical route to self-consistent methods of property calculations and are used by the "LApp" plastic properties code, a PC version of which is included with popLA. Additionally, programs are supplied for the rapid assessment of R-values or yield surface sections in cubic metal sheets can be made from the spherical harmonic coefficients using the Taylor $^{7}$ model of polycrystalline plasticity as described by Viana et. $\mathrm{al}^{8}$.

\section{INTEGRATION}

The authors have attempted as far as possible to maintain a consistent "user interface" for the software. Prompts are provided at all points where user input is needed, and where appropriate, default inputs are suggested. The consistent file 


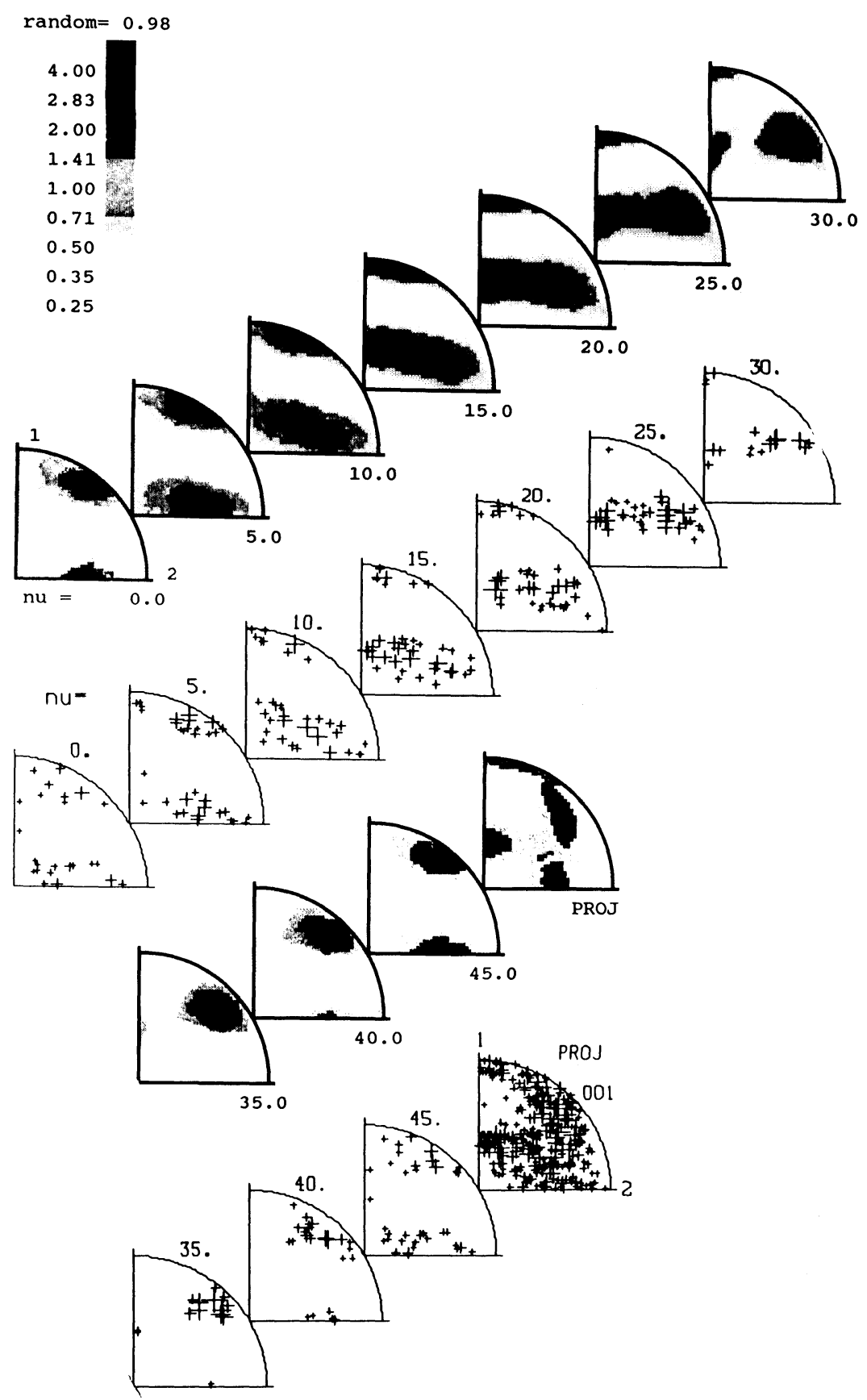

Figure 2. Orientation distribution of copper deformed in plane strain compression to a von Mises strain of 1.1, presented as constant $n u$ sections in equal-area projection. Also shown is the same distribution after conversion to weighted discrete grains. 


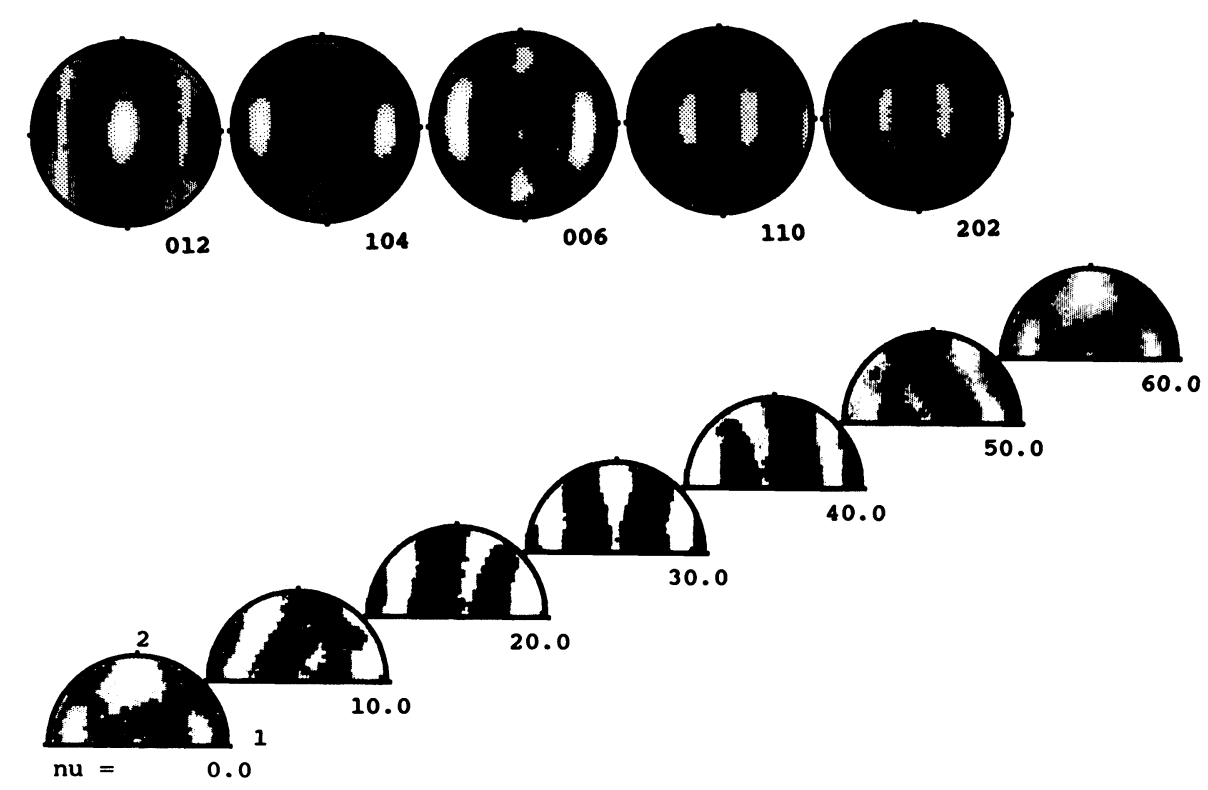

Figure 3. Neutron pole figures from a deformed calcite (trigonal) sample, and the corresponding constant nu (oblique) sections of the orientation distribution. The sample was assumed to have monoclinic statistical symmetry. The data were analysed by the WIMV method.

structure allows easy transfer of data from one program to another within the package. Additionally, a menu is available from which the various programs may be invoked without the need to remember the many individual program names.

\section{ACKNOWLEDGEMENTS}

The authors wish to thank L. Stixrude, M.A. Przystupa, T.G. Schofield, A.C. Biondo, R.E. Bolmaro, T. Ozturk, J. Hirsch, C.N. Tome and G.R. Canova, whose programming contributions are incorporated in the package. The major portion of this work was supported by the Division of Basic Energy Sciences, U.S. Department of Energy and by the Institute of Geophysics and Planetary Physics of the University of California and Los Alamos National Laboratory.

\section{REFERENCES}

1. H.-J. Bunge. Z. Metallk. 56, 872 (1965).

2. R.J. Roe. J. Appl. Phys. 36, 2024 (1965).

3. S. Matthies and G.W. Vinel. phys. stat. sol.(b) 112, K111 (1982)

4. U.F. Kocks. in 8th Intl. Conf. on Textures of Materials, J.S. Kallend and G. Gottstein eds. (TMS-AIME, Warrendale, PA, USA, 1988) 69. 
5. U.F. Kocks, J.S. Kallend and A.C. Biondo, this volume.

6. J.S. Kallend, U.F. Kocks, A.D. Rollett and H.-R. Wenk. Mater. Sci. Eng., in press.

7. G.I. Taylor, J. Inst. Metals, 62, 307 (1938).

8. C.S. da C. Viana, J.S. Kallend and G.J. Davies. Int. J. Mech. Sci. 21, 355 (1979)

9. H.-R. Wenk and U.F. Kocks. Metall. Trans. 18A, 1083 (1987).

To obtain the popLA package, write to :

L. Lauer

Center for Materials Science

LANL K-765

Los Alamos, NM 87545, USA 